\title{
Hubungan Antara Komponen Permukiman Dan Keberhasilan Metode Bank SAMPah Dalam PengelolaAn SAMPaH Berkelanjutan Di Kota SURAKARTA
}

\author{
Mohamad Nuriman, Soedwiwahjono, Rufia Andisetyana Putri \\ Program Studi Perencanaan Wilayah dan Kota \\ Jurusan Arsitektur, Fakultas Teknik \\ Universitas Sebelas Maret, Surakarta \\ Email: mohnuriman@gmail.com
}

\begin{abstract}
Garbage was one of the environmental problems. As time goes by, garbage has become that cause new problems like water pollution, air pollution, flood and others. Most of people seeing garbage as unused items that cannot work and then system of garbage management by government did not function properly.

Today begins to develop a sustainable garbage management with community role to managing garbage. One of the part of sustainable garbage management is garbage bank method. In sustainable garbage management method particularly with garbage bank must be adjusted and considered by environmental conditions local settlements in order to successful, the aspect related to housing components such as physical environment, economy, community, law, culture and the availability of utilities have an important relation in the development of sustainable garbage management.

This research wants to know what is relationship between housing components and success of garbage bank method on sustainable garbage management, and the next step is identfy housing components and success of garbage bank in two area, RW IX Kelurahan Kadipiro and RW II Kelurahan Gajahan with scoring analyse and finally do the crosstab analyse to determine the relationship between both of them.

The conclusion is a housing components with individual aspect such as nature, society, shell and network have important relation with the success of garbage bank method. This research is to identfy the housing components and success of garbage bank method in two case studies, so we can determine the relationship between both of them in RW IX Kelurahan Kadipiro and RW II Kelurahan Gajahan, Surakarta.
\end{abstract}

Keywords: sustainable garbage management, garbage bank, housing components

\section{PENDAHULUAN}

Permasalahan sampah merupakan salah satu permasalahan lingkungan yang sangat rumit penanganannya, bahkan saat ini sampah telah menjadi masalah sendiri yang turut menimbulkan permasalahan baru seperti pencemaran air, pencemaran tanah, pencemaran udara, banjir dan lain sebagainya. Selama ini sebagian besar masyarakat memandang sampah sebagai barang sisa yang tidak berguna, bukan sebagai sebagai sumber daya yang perlu dimanfaatkan. Penanganan sampah juga masih bertumpu pada pendekatan akhir (end of pipe) yaitu sampah dikumpulkan, diangkut dan dibuang ke tempat pembuangan akhir sampah (Sufianti, 2011).

Dewasa ini mulai dikembangkan sistem pengelolaan sampah berkelanjutan dengan penekanan peran masyarakat dalam mengelola sampah. Salah satu teknik pengelolaan sampah berkelanjutan adalah bank sampah. Dalam 
pengelolaan sampah berkelanjutan khususnya dengan metode bank sampah harus disesuaikan dan dipertimbangkan dengan kondisi lingkungan permukiman setempat agar berhasil, aspek -aspek terkait komponen permukiman seperti kondisi-kondisi fisik, ekonomi, masyarakat, hukum, budaya serta ketersediaan sarana-prasarana pendukung memiliki peran dalam pengembangan dan keoptimalan pengelolaan sampah berkelanjutan tersebut.

Tujuan dari penelitian ini adalah untuk mengetahui hubungan komponen permukiman terhadap keberhasilan metode bank sampah dalam pengelolaan sampah berkelanjutan di dua studi kasus yaitu RW IX Kelurahan Kadipiro dan RW II Kelurahan Gajahan, Kota Surakarta.

\section{METODE}

\subsection{Ruang Lingkup}

Ruang lingkup area dalam penelitian ini terdapat dua studi kasus yaitu di RW IX Kelurahan Kadipiro dan RW II Kelurahan Gajahan. Kedua area tersebut merupakan lingkungan permukiman yang menerapkan pengelolaan sampah berbasis masyarakat dengan metode bank sampah. Kelurahan Kadipiro merupakan kelurahan yang mengaplikasikan metode bank sampah pertama dan menjadi pilot project bagi kelurahan lain di Kota Surakarta dan RW II Kelurahan Gajahan melaksanakan metode bank sampah dalam pengelolaan sampah di lingkungannya dan memberikan sebuah proses permberdayaan masyarakat yang baik dalam mengelola lingkungannya. Komponen permukiman terdiri dari man, nature, shell, society dan network (Doxiadis, 1997) dan aspek keberhasilan metode bank sampah dalam pengelolaan sampah berkelanjutan terdiri dari aspek ekologis, sosial dan ekonomi (Kusumantoro, 2010).

\subsection{Metode Analisis}

Penelitian ini menggunakan metode analisa skoring dan tabulasi silang. Analisis tersebut dapat dijabarkan, antara lain: a. Mengidentifikasi komponen permukiman dengan menggunakan pembobotan dengan indikator penilaian yang telah dirumuskan.

b. Mengidentifikasi keberhasilan metode bank sampah dalam pengelolaan sampah berkelanjutan dengan indikator penilaian yang telah dirumuskan.

c. Menganalisis hubungan komponen permukiman terhadap keberhasilan metode bank sampah dalam pengelolaan sampah berkelanjutan dengan analisis tabulasi silang. Penentuan hubungan dirumuskan dalam kategori yang ditentukan dalam tabel berikut (lihat lampiran 1).

\section{HASIL DAN PEMBAHASAN}

\subsection{Identifikasi Komponen Permukiman}

Identifikasi komponen permukiman dengan menggunakan skor atau pembobotan yang meliputi nature atau kondisi fisik alam yang terdiri dari topografi, geologi dan iklim, society atau keadaan masyarakat/komunitas sosial yang terdiri dari struktur penduduk, jenis pekerjaan, tingkat pendapatan penduduk, kelembagaan dan pola budaya, kemudian shell atau bangunan/sarana pendukung yang terdiri dari keseluruhan sarana pendukung dalam pelaksanaan bank sampah dan yang terakhir aspek network atau jaringan/prasarana pendukung yang terdiri dari keseluruhan prasarana metode bank sampah di kedua unit lingkungan tersebut secara umum memiliki kondisi yang hampir sama, karena dari aspek yang diteliti menggambarkan karakteristik sejenis dalam kesatuan Kota Surakarta (lihat lampiran 2). Namun, terjadi perbedaan dalam aspek shell dan network yaitu kondisi sarana dan prasarana dalam pelaksanaan metode bank sampah di RW IX Kelurahan Kadipiro yang lebih baik ketersediaan dan keadaannya dibandingkan dengan di RW II Kelurahan Gajahan.

\subsection{Identifikasi Keberhasilan Metode Bank Sampah dalam Pengelolaan Sampah Berkelanjutan}


Identifikasi keberhasilan metode bank sampah dengan menggunakan skor atau pembobotan yang meliputi aspek ekologis, sosial dan ekonomi di kedua studi kasus secara garis besar dapat dijelaskan terdapat perbedaan di dalam penilaian (lihat lampiran 3). Hal ini disebabkan berdasarkan tinjauan di lapangan, proses pelaksanaan bank sampah yang terdapat di RW IX Kelurahan Kadipiro telah berlangsung lebih lama dibandingkan dengan bank sampah yang terdapat di RW II Kelurahan Gajahan. Banyak kendala yang dihadapi oleh RW II Kelurahan Gajahan seperti belum terbentuknya antusiasme warga dan ketersediaan sarana prasarana yang kurang sehingga indikator-indikator keberhasilan dalam ketiga aspek tersebut tidak tercapai dengan baik. Sedangkan di RW IX Kelurahan Kadipiro proses pelaksanaan bank sampah yang notabene hampir 3 tahun dijalankan sudah berlangsung dengan baik, antusiasme warga sudah terbentuk karena merasa bahwa kehadiran bank sampah dapat memberikan hal-hal positif bagi lingkungan maupun masyarakat ditambah dengan kondisi permukiman yang mendukung keberlangsungan dan penerapan metode bank sampah ini sehingga indikator dalam keberhasilan dapat tercapai.

\subsection{Hubungan Komponen Permukiman Terhadap Keberhasilan Metode Bank Sampah}

$\begin{array}{ccr}\text { Untuk } & \text { mengetahui } & \text { hubungan } \\ \text { komponen } & \text { permukiman } & \text { terhadap }\end{array}$
keberhasilan metode bank sampah dengan menggunakan analisis tabulasi silang (lihat lampiran 4). Berdasarkan hasil analisis di atas, hubungan komponen permukiman terhadap keberhasilan metode bank sampah dalam pengelolaan sampah berkelanjutan di RW IX Kelurahan Kadipiro mendapatkan nilai 36 yang masuk kategori hubungan kuat (30-36) sedangkan untuk di RW II Kelurahan Gajahan mendapatkan nilai 28 yang berarti masuk dalam kategori hubungan sedang (21-
29). Kategori kuat memiliki pemahaman bahwa naik turunnya salah satu variabel akan menyebabkan naiknya variabel yang satunya dan naik atau turunnya salah satu variabel bisa dijelaskan dengan variabel yang lain dengan sepenuhnya tanpa kesalahan sedikit pun. Untuk hubungan kategori sedang memiliki pemahaman bahwa ketika salah satu variabel naik maka tidak berarti variabel lain akan naik.

Dalam penjelasan mengenai perbedaan hasil kategori hubungan, kedua studi kasus memiliki nilai yang berbeda dalam penilaian hubungan komponen permukiman terhadap keberhasilan metode bank sampah dalam pengelolaan sampah berkelanjutan karena perbedaan karakteristik dalam masingmasing aspek yang dinilai dan perbedaan waktu pelaksanaan. RW IX Kelurahan Kadipiro dan RW II Kelurahan Gajahan memiliki nilai yang hampir sama dalam penilaian di aspek komponen permukiman namun pada aspek keberhasilan metode bank sampah kedua studi kasus ini memiliki nilai yang berbeda sehingga pada matriks hubungan terlihat perbedaan penilaian di masing-masing studi kasus.

\section{KESIMPULAN}

Hubungan antara komponen permukiman dan keberhasilan metode bank sampah di sebuah lingkungan cenderung kuat. Masingmasing bagian dari komponen permukiman memberikan sebuah dukungan terhadap aspek keberhasilan metode bank sampah tersebut. Kemudian terkait kedua studi kasus yang dijadikan sebagai sampel penilaian terhadap hubungan dua variabel ini, faktor lama pelaksanaan metode bank sampah menjadi pembeda dalam ukuran penilaian, RW IX Kelurahan Kadipiro menjadi unit lingkungan yang lebih baik dalam pelaksanaan bank sampah dibandingkan dengan unit lingkungan RW II Kelurahan Gajahan. 


\section{REFERENSI}

Sufianti, Ely. 2011. Perencanaan Kolaborasi Dalam Pengelolaan Sampah Sebagai Pembangunan Lingkungan Yang Berkelanjutan. STIA LAN Bandung

Doxiadis, Constantinos. 1997. Ekistics, an Introduction to the Science of Human Settlements. Hutchinson of London

Kusumantoro, Sri Muhammad. 2013. Menggerakkan Bank Sampah. Kreasi Wacana: Bantul 


\section{LAMPIRAN}

\section{Lampiran 1}

\begin{tabular}{|c|c|}
\hline Interval & Kategori \\
\hline $30-36$ & Kuat \\
\hline $21-29$ & Sedang \\
\hline $12-20$ & Rendah \\
\hline
\end{tabular}

\section{Lampiran 2}

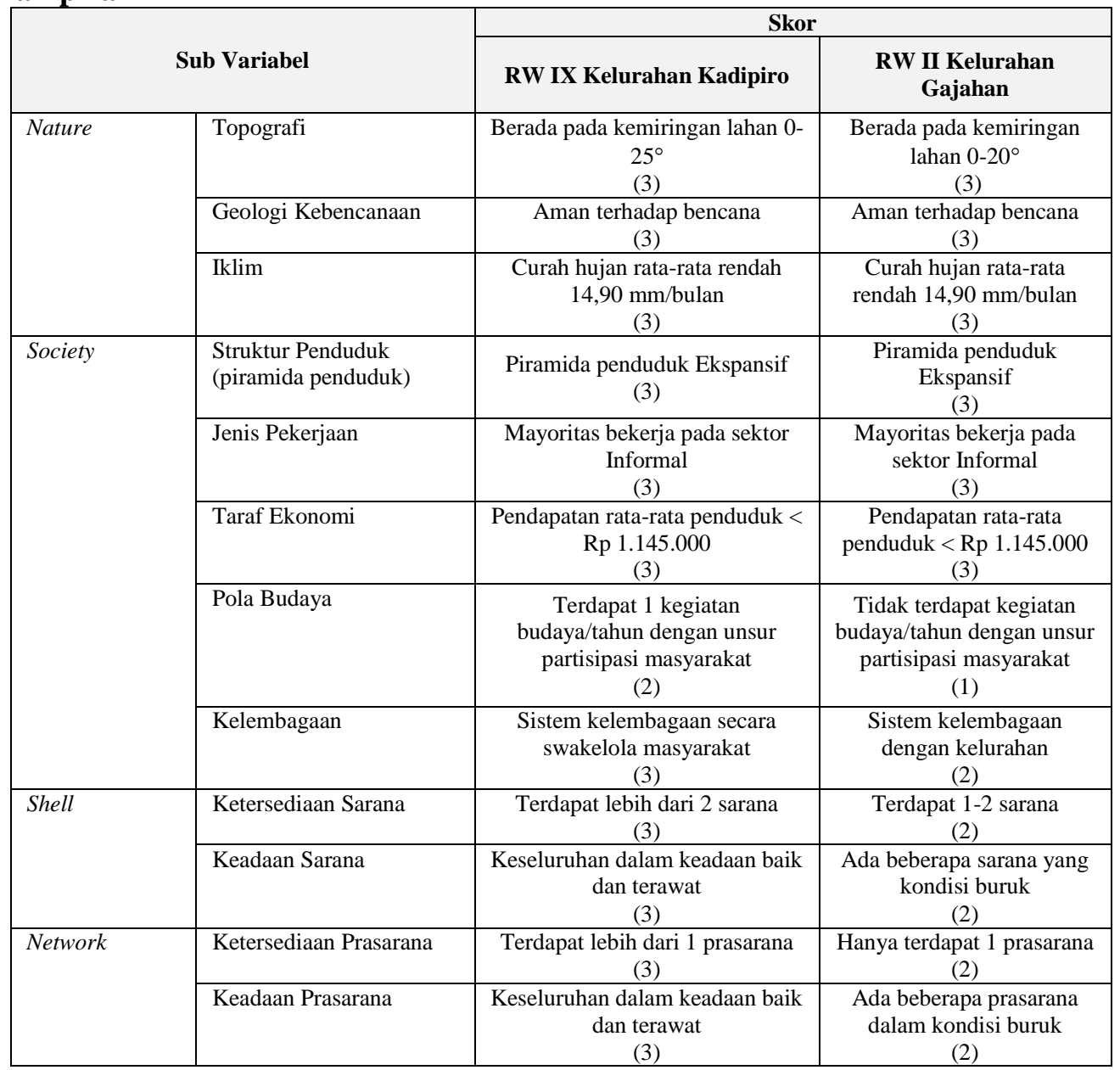




\section{Lampiran 3}

\begin{tabular}{|c|c|c|c|}
\hline \multirow{2}{*}{\multicolumn{2}{|c|}{ Sub Variabel }} & \multicolumn{2}{|c|}{ Skor } \\
\hline & & \multirow{2}{*}{ 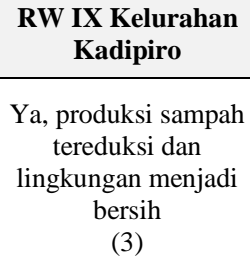 } & \multirow{2}{*}{$\begin{array}{c}\text { RW II Kelurahan } \\
\text { Gajahan } \\
\text { Ya, produksi sampah } \\
\text { tereduksi dan lingkungan } \\
\text { menjadi bersih } \\
\text { (3) }\end{array}$} \\
\hline Aspek Ekologis & $\begin{array}{l}\text { Jumlah sampah } \\
\text { tereduksi dan } \\
\text { keadaan lingkungan } \\
\text { yang bersih }\end{array}$ & & \\
\hline \multirow[t]{2}{*}{ Aspek Ekonomi } & $\begin{array}{l}\text { Memberikan } \\
\text { maanfaat ekonomi } \\
\text { dan menjadi } \\
\text { sumber pendapatan } \\
\text { baru }\end{array}$ & \multirow{2}{*}{$\begin{array}{c}\text { Baik, } 2 \text { aspek dalam } \\
\text { indikator terpenuhi } \\
\text { (3) }\end{array}$} & \multirow{2}{*}{$\begin{array}{c}\text { Sedang, hanya } 1 \text { aspek } \\
\text { dalam indikator terpenuhi } \\
(2)\end{array}$} \\
\hline & $\begin{array}{l}\text { Berkembangnya } \\
\text { usaha daur ulang } \\
\text { sampah }\end{array}$ & & \\
\hline \multirow[t]{2}{*}{ Aspek Sosial } & $\begin{array}{l}\text { Memberikan } \\
\text { kesibukan positif } \\
\text { bagi warga } \\
\text { terutama ibu-ibu } \\
\text { rumah tangga } \\
\text { dalam mengelola } \\
\text { sampah menjadi } \\
\text { produk bernilai } \\
\end{array}$ & \multirow[t]{2}{*}{$\begin{array}{c}\text { Baik, } 2 \text { aspek dalam } \\
\text { indikator terpenuhi } \\
\text { (3) }\end{array}$} & \multirow[t]{2}{*}{$\begin{array}{c}\text { Sedang, hanya } 1 \text { aspek } \\
\text { dalam indikator terpenuhi } \\
(2)\end{array}$} \\
\hline & $\begin{array}{l}\text { Masyarakat tidak } \\
\text { berlangganan lagi } \\
\text { ke petugas } \\
\text { kebersihan }\end{array}$ & & \\
\hline
\end{tabular}

\section{Lampiran 4}

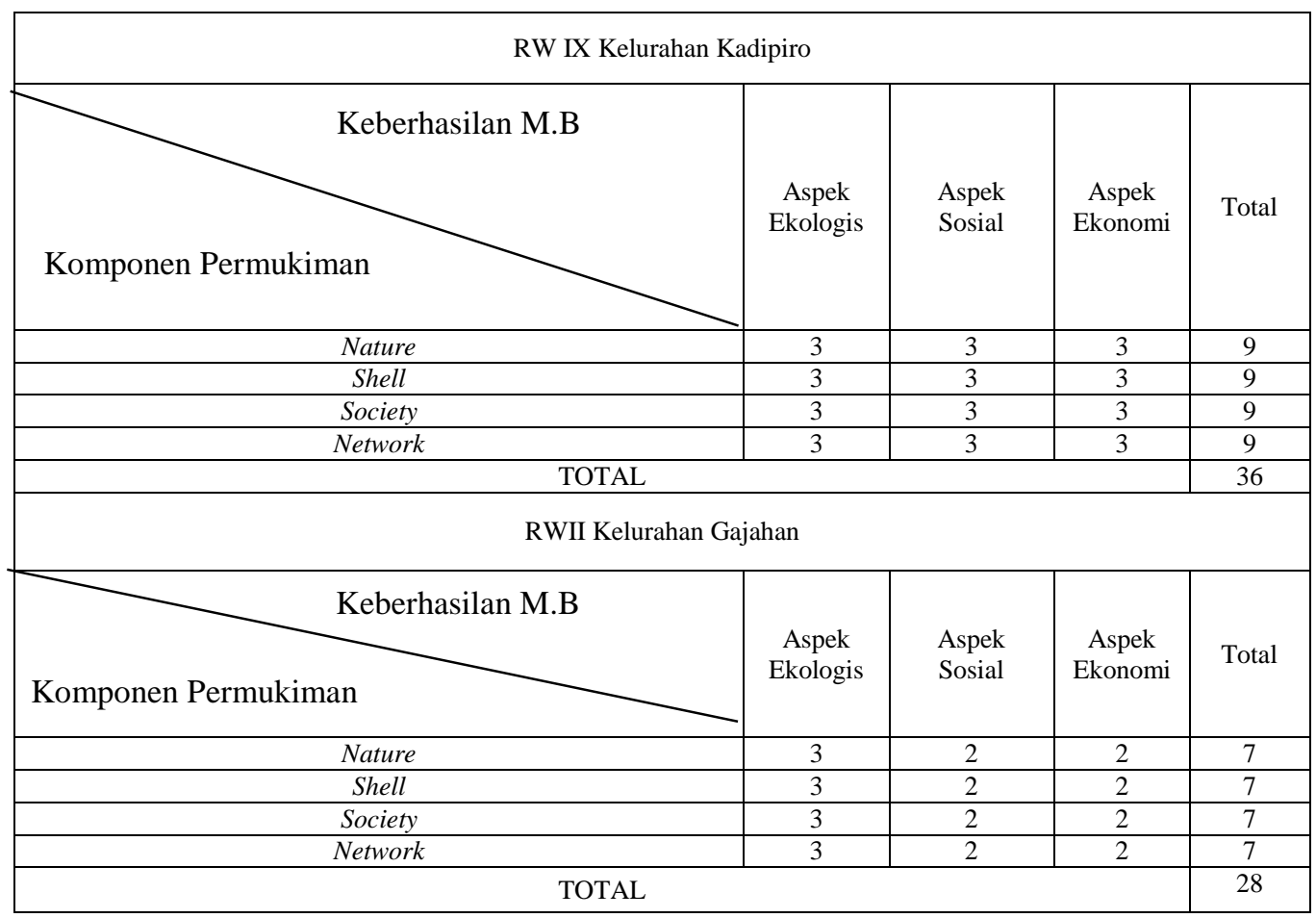

